\title{
ANĀLISE CRÍTICA DA UTILIZAC̣ĀO DAS FOLHAS DE CONTROLE NAS UNIDADES DE TERAPIA INTENSIVA (UTIS)
}

\author{
Edna Ikumi Umebayashi Takahashi ${ }^{1}$, Ana Maria Kazue Miyadahira ${ }^{1}$, \\ Miako Kimura ${ }^{2}$
}

TAKAHASHI, E.I.U. et alii. Análisc crítica da utilização das follas de controle nas unidades de terapia intensiva (UTIs). Rev. Bras. Enf., Brasília, 37 (3/4): 257 261, jul./dez. 1984.

\begin{abstract}
RESUMO. Trata-se de uma análise crítica da utilização das folhas de controle nas unidades de tratamento intensivo de um hospital-escola. Para essa análise foi feito um levantamento do impresso empregado nas doze UTIs desse referido hospital, como também foram coletados alguns dados referentes à sua utilização. A análise dos resultados nos permite refletir sobre a inadequação das folhas de controle por não retratarem uma assistência de enfermagem sistematizada aos pacientes, nas unidades pesquisadas.
\end{abstract}

ABSTRACT. This is a critical analysis on the use of control records in 12 intensive care units of a school hospital. The data obtained showed that the control records are inadequate and do not demonstrate a systematic nursing care given to patients in those units.

\section{INTRODUÇÃO}

A necessidade da consolidação de um corpo de conhecimentos tem voltado a atenção do enfermeiro para a definição de um método próprio de assistência.

Em busca de tal meta e em prol de uma enlermagem mais científica e qualificada, tentativas de implementaçĩo de uma assistência sistematizada têm sido feitas. Algumas dessas, atingiram com sucesso o objetivo proposto e outras ainda estão com dificuldades em sua efe tivação.

FRIEDLANDER (1983) acredita que o sucesso ou insucesso na implantação desse sistema de trabalho cabe ao apoio, colaboração e interesse das chefias de enfermiagem e do preparo rigoroso constante e sistemático dos enfermeiros.
KOCH \& OKA (1977) sugerem que cada profissional faça uma aplicação e avaliação de uma sistemática de assistência dentro da sua área de atuação.

Nas unidades de terapia intensiva (UTIs), a consecuçĩo dos objetivos a cla increntes depende principalmente do desempenho planejado da equipe de enfermagem. A estratégia operacional de uma UTI se torna possível quando existe uma enfermagem especialmente preparada para assistir o paciente crítico.

WHIPPLE (1980) considera que UTI consiste em uma oportunidade e desafio para a enfermagem: oportunidade para desempenhar um papel profissional voltado ao tratamento da enfermidade crítica e desafio para enfrentar eficazmente as responsabilidades profissionais e técnicas aumentadas.

1. Professores Assistentes de disciplina de Enfermagem Médico-Cirúrgica da Escola de Enfermagem da USP, enfermeiras.

2. Auxiliar de Ensino da disciplina de Enfermagem Médico-Cirúrgica da Escola de Enfermagem da USP, enfermeira. 
O sucesso do desempenho profissional em UTI, depende da maneira como o enfermeiro encara e assume o seu papel e, principalmente, de uma abordagem sistematizada da assistência a ser prestada. Esta sistematização de assistência se torna essencial em UTI, pela própria situação crítica do paciente grave e pela dinânuica intensiva dessas unidades.

Portanto, é primordial que a assistência seja pianejada com base numa sistemática que adote E metodologia cient ífica. Não importa a terminologia utilizada para definir essa metodologia, ou mesmo, a sua forma, mas sim, que seja implementada para atender desde os problemas mais simples do paciente até os problemas mais complexos, nas esferas biopsicossócio-espirituais.

Sendo o planejamento escrito ou registrado, de alguma forma, proporniona uma comunicação melhor e mais consistente entre os membros da equipe de saúde, permitindo a continuidade de um alto padrão de assistência.

Na maioria das UTls, temos observado que a implementação de uma sistemática de assistência tem sido una preocupaçĩo constante. No entanto, as características dos pacientes de UTI parecem tornar impróprios alguns modelos preconizados.

Além da dificuldade em conseguir adequar um modelo de acordo com as características do paciente grave, deparamos também com a dificuldade em evidenciar o paciente nas suas esferas biopsicossócio-espirituais. Muitas vezes, a esfera biológica é priorizada em função da gravidade das condiçôes físicas em que se encontra o paciente e pela necessidade premente de lutar pela sobrevivência do doente. No entanto, por todo esse contexto de risco de vida, o componente humanístico do relacionamento enfermeiro-paciente se torna ainda mais rico, exigindo do profissional uma atuação também efetiva nas demais esferas. Da mesma forma, GOMES (1978) considera necessária uma atitude da equipe, não somente orientada para o aproveitamento das facilidades técnicals que a UTI oferece, como também conscientizada da prioridade do relacionamento humano como fator essencial à segurança e apoio emocional ao paciente.

Entretanto, como conseguir cnfalizar todos esses pontos de forma prática, concisa e efetiva? Por não se tratar de tarefa fácil, observa-se que a forma como a sistematização da assistência em UTI pode ser efetivada ainda não está claramente definida. MIZUTANI (1978) considera que podem ser criados os mais diversos tipos de instrumento que visem uma assistência sistematizada, desde que práticos e objetivos. O que se tem verificado é que, em função da atividade incessante do enfermeiro nas UTIs, parece haver uma tendência para a utilização de impressos simplificados que não somente sirvam para registrar os dados vitais dos pacientes, mas que se constituam em instrumentos que retratem um planejamənto da assistência de enfermagem e possibilitem a evolução do paciente e a avaliação dessa assistência. Dentre os impressos util izados nas UTIs, o que mais expressa as atividades do enfermeiro é aquele no qual ele registra os parâmetros controlados do paciente, isto é, as folhas de controle.

Diante do exposto, optamos por analisar o conteúdo e a utilização, pelo enfermeiro, das folhas de controle nas UTls de um hospitalescola.

O propósito fundamental dessa análise é de possibilitar aos enfermeiros que atuam em UTIs, um momento de reflexão quanto à utilização das folhas de controle preconizadas em suas respectivas unidades.

\section{METODOLOGIA}

O estudo foi realizado em um hospital-escola, tendo sido feito un levantamento das follais de controle de pacientes nas doze U'TIs desse mesmo hospital. Nesse levantamento, além do impresso empregado, coletaram-sc alguns dados referentes à sua utilização bem como suas vantagens e desvantagens.

\section{RESULTADOS E DISCUSSÃO}

Das doze unidades pesquisadas, todas utilizam follhas de controle, sendo que foram identificados nove diferentes modelos. Duas unidades utilizam um mesmo modelo e três unidades utilizam igualmente um outro modelo. Os demais diferiam entre si em tamanho, forma e conteúdo. Na descrição dos resultados faremos sempre referência às follhas, pois apesar de alguns modelos iguais, as unidades sĩo independentes entre si e a sua utilização pode dilerir de um local para outro. Além disso, interessa para esse estudo, a análise do global e não das folhas isoladamente.

\section{Conteúdo das folhas de controle}

A gravidade das condições do paciente internado em UTI se reflete significativamente no dese- 
quilíbrio dos parâmetros considerados vitais. Em virtude, talvez, deste fato, observal-se uma preocupação expressa nas follhas de controle analisadas, em evidenciar os sinais vitais em primeiro plano. Os sinais vitais mais comumente encontrados são temperatura $(\mathrm{T})$, pulso $(\mathrm{P})$, respiração $(\mathrm{R})$ e pressão arterial (PA). A pressão venosa central (PVC) foi encontrada em seis folhas e a frequiência cardíaca (FC) em quatro folhas. Em duas folhas havia espaços vazios na coluna referente aos sinais vitais, possibilitando o acréscimo de outros parâmetros. Entretanto, para todos eles só havia espaço para registro dos dados quantitativos. Acredita-se, porém, que para uma avaliação mais expressiva, as informaçōes qualitativas devam ser tão valorizadas quanto as quantitativas.

Em dez unidades, as folhas permitem o registro de dados para controle hídrico. Em apenas uma unidade, Unidade de Queimados, pelas características próprias dos pacientes que assiste e pela necessidade de um rigoroso controle hídrico, há espaço suficiente para especificar qualitativamente os diferentes volumes gamhos e perdidos. Nos demais, esse controle é baseado praticamente nos líquidos ingeridos e/ou administrados por via parenteral e nas perdas por diurese. Em algumas follhas (três a cinco) são incluídas ainda as perdas por drenos, sondas, vômitos e sudorese. É importante ressaltar que neste item de controle hídrico, não sejam somente registrados os dados relativos ao volume perdido e ganho. Há necessidade que se faça o balanço hídrico, fator de grande importância para avaliação da homeostase.

Outros cuidados como exercício respiratório, aspiração orotraqueal, mudança de decúbito e higiene também são encontrados em quatro a cinco diferentes folhas. Ainda, o controle de peso, a troca de cânula traqueal, a troca de frascos de drenagem foram encontrados em dois modelos. Apenas em uma folha existe um espaço que é empregado improvisadamente para prescrição de enfermagem.

Da observação acima, constata-se que os modelos que contêm cuidados específicos de enfermagem não chegam à metade do total pesquisado, sendo que aqueles que os contêm estão incompletos. Apenas uma unidade fez exceção ao estabelecer um espaço improvisado para a pres. crição de enfermagem. Ressaltamos que a folha de controle é o impresso mais utilizado pela enfermeira e sua equipe, nas Unidades estudadas. Constata-se, entretanto, que esse impresso, mais apropriado para retratar as condiçðes gerais do paciente de UTI, é utilizado mais freqüente e prioritariamente para o registro de alguns parâmetros, não visando um planejamento global de enfermagem.

Desta forma, vemos que as esferas psicossócioespirituais nem sequer são mencionadas nas diferentes folhas, excetuando uma que, talvez na tentativa de abrangê-las, tem um espaço para o registro de Problemas e Queixas. A organização do conteúdo e a utilização das folhas de controle refletem a preocupação em salientar os aspectos da área biológica. De certa forma, isto é esperado em funçĩo do grande comprometimento físico dos pacientes de UTI. No entanto, a própria condição de risco de vida do paciente grave, entre outros, torna evidente a necessidade e a importância do componente humanístico, na assistência de enfermagem. Acreditamos que isso se efetive quando a enfermeira voltar sua atenção para as demais esferas do paciente, que não somente a física. Muitas vezes questionamos até onde vai a nossa compotência para lidar com aspectos que transcendem a área biológica. Será que ao realizarmos aquilo que especificamente nos compete, com respeito, compreensão e interesse por aquele a quem assistimos, não estaríamos minimizando grande parte dos problemas relativos âs esferas psicossócioespirituais? Essa postura de respeito pela pessoa, mesmo em condições críticas, de compreensão dos problemas apresentados e de interesse em ajudar na soluçĩo desses problemas não deveria ser da competência de todo enfermeiro?

Prosseguindo a análise, verificamos que dez folhas apresentam um espaço para observaçðes. Entretanto, dessas dez somente três permitem ou possibilitam uma evolução de enfermagem. Apesar da existência desse espaço para observações, com exceção de uma unidade, todas as demais utilizam um outro impresso comum a todo hospital para anotações de enfermagem. Verificase, portanto, que em nove unidades ocorre duplicação de espaço para anotação de enfermagem. No entanto, para o presente estudo, não foi possível analisar o conteúdo das anotaçбes feitas pela enfermagem, não sendo possível, dessa maneira, verificar a ocorrência de duplicação de informações. Da mesma forma, não foi possível verificar se os enfermeiros e sua equipe consideram os aspectos relacionados às esferas psicossócioespirituais dos pacientes, pelo registro no impresso das anotaçбes de enfermagem. Se tais aspectos são de uma forma ou de outra valorizados pela enfermagem, um espaço deveria ser destinado a 
eles, por se tratarem de aspectos imprescindíveis para a compreensão do paciente na sua totalidade. Enfatizamos mais uma vez que, na maioria das unidades, os dois impressos referidos acima (folhas de controle e anotaçóes de enfermagem) são os únicos utilizados pela enfermagem e que, portanto, deveriam retratar a metodologia de assistência empregada pelo enfermeiro.

Outros itens como prescrição médica, exames laboratoriais, condiçoes de ventiladores, são incluídos em uma ou outra folha.

\section{Utilização das folhas de controle}

$\mathrm{Na}$ tentativa de identificar o envolvimento do profissional enfermeiro no planejamento dos controles realizados por ele e sua equipe, buscou-se levantar a quem cabia a determinação da frequiência e dos parâmetros a serem controlados.

Verificou-se que em sete unidades, o enfermeiro juntamente com o médico são os responsáveis por essa determinação e, em cinco unidades, cabe somente a enfermeiro.

Entretanto, quando foi questionado em que se baseava a determinação da freqüência e dos parâmetros a serem controlados, constatou-se que, em seis unidades, os controles siio leitos de acordo com a rotina estabelecida, em cinco, de acordo com a rotina e a condição do paciente e, em apenas uma, se estabelece os controles de acordo com as condições do paciente.

Denota-se por essas respostas, a incoerência entre a finalidade e a forma de utilização das follhas de controle. Se os cuidados, ou melhor, os controles são estabelecidos rotineiramente, isto é, sem um planejamento prévio individualizado, a determinação desses controles depende exclusivamente da rotina pré-estabelecida nas unidades, o que foge completamente de uma filosofia de assistência individualizada. Mesmo nas unidades em que se mencionou considerar a condição do paciente além da rotina, na realidade o controle de início é rotineiro. Somente após a modificação do estado geral do paciente, ou seja, de seu agravamento, esse controle foge aos padróes estabelecidos nas unidades. Isto denota a pouca importância que é dada ao carater preventivo de uma assistência planejada.

Portanto, pelas respostas obtidas, constata-se que de doze unidades somente em uma o enfermeiro planeja a assistência a ser prestada, tomando como base para o seu planejamento, a avaliação das condiçðes do paciente.
Por sua vez, a avaliação dos parâmetros controlados é feita por enfermeiro e médico em nove unidades, somerte por médico em duas unidades e somente por enfermeiro em uma unidade. Se o enfermeiro realmente tem a preocupação de analisar e avaliar os dados obtidos nos controles, ele pode se questionar quanto à viabilidade de serem estabelecidas rotinas para assistência dos pacientes de UTI. Sabe-se que rotinas administrativas são estabelecidas para facilitar o desenvolvimento das atividades pertinentes a uma assistência de enfermagem. Entretanto, as rotinas existentes não devem ser a base para a assistência, pois assim, ela deixa de ser direcionada às necessidades de cada paciente.

Tais dados nos mostram a falta de preparo dos enfermeiros na utilização de um método científico de assistência. Questionamos, no entanto, até onde os órgãos formadores têm se preocupado em preparar o seu produto para tal assistência. Se essa preocupação ainda não existe a nível de algumas escolas, devemos lembrar da existência do Projeto de Lei nọ 60/82 do exercício profissional (COFEN 1980), que legalizará a realização da prescrição de enfermagem pelo enfermeiro como parte de sua atividade profissional.

De qualquer forma, acreditamos que o cnfermeiro tenha preparo e deva utilizar o seu potencial crítico, direcionando-o para análise e reflexão da sua prática. Acreditamos ser esse o primeiro passo com o qual, cada um de nós poderá contribuir para o fortalecimento do enfermeiro enquanto profissional e da enfermagem enquanto profissão.

\section{Vantagens e desvantagens}

As principais vantagens citadas pelos enfermeiros com as folhas de controle utilizadas nas respectivas unidades são apresentadas a seguir, em ordem decrescente de citação: permite visão geral do paciente; é prática e objetiva; permite controle das 24 horas e é de fácil manipulação.

Como desvantagens, os seguintes pontos foram colocados em ordem decrescente de citação: é incompleta (falta prescrição de enfermagem, espaço para anotaçốes); tem dados em excesso (cm algumas unidades nem todos os dados contidos nas follhas são utilizados); é complexa; tem tamanho impróprio e não é anexada à papeleta.

Em vista das diferentes colocaçðes quanto às vantagens e desvantagens das folhas de controle, verifica-se a dúvida que o enfermeiro tem quanto à sua finalidade e a relação das mesmas como parte 
de uma assistência sistematizada. A utilização das folhas tais quais são apresentadas ño significa que elas niio podem estar vinculadas al um método assistencial de enfermagem, contudo, é essencial que, para a sua utilização, as folhas de controles estejam inseridas dentro de uma filosofia compartilhada por toda a equipe, que vise primordialmente, uma assistência de enfermagem planejada e global.

Desta forma, verifica-se a inadequação de introduzir modelos de outros locais, sem uma avaliação prévia das condiçøes estruturais de cada unidade bem como da análise das especificidades dos tratamentos e condiçōes do paciente.

Nota-se ainda, pelas vantagens e desvantagens citadas, a necessidades sentida pelo enfermeiro de se atribuir outras qualidades às denominadas folhas de controle, ampliando a sua abrangência, sem contudo alterar as facilidades por elas oferecidas.

\section{CONCLUSÓES}

Em vista dos aspectos analisados anteriormente, concluímos:

1. As folhas de controle consideram em seu conteúdo alguns cuidados da área biológica dentre os quais o controle dos sinais vitais e o controle hídrico, nđo incluindo aspectos psicossócio-espirituais dos pacientes graves.
2. As folhas de controle e o impresso de anotaçōes de enfermagem são os únicos impressos utilizados pela enfermagem nas UTIs pesquisadas.

3. As folhas de controle são usadas mais freqüentemente para simples registro dos dados obtidos nos controles feitos pela enfermagem, não incluindo outros aspectos pertinentes à problemática do paciente na UTI.

4. Não existe um planejamento prévio dos cuidados realizados e anotados nas folhas de controle. Esses cuidados são realizados com base em rotinas estabelecidas nas unidades.

5. A utilização das folhas de controle, tal como se faz, não permite caracterizar uma assistência de enfermagem sistematizada nas UTls pesquisadas.

Com base na análise feita no presente estudo quanto à utilização das folhas de controle, consideramos oportuno sugerir que estudos sejam realizados pelos enfermeiros com o intuito de analisar a validade dos instrumentos ora utilizados em suas respectivas unidades, bem como de refletir sobre a sua atuação e sua contribuição para a consolidiç̃̃o de um corpo de conhecimentos da profissio.

TAKAHASHI, F.I.U. ct alii. Critical analysis about the use of control records in intcnsive carre units. Rev. Bras. Enf., Brasília, 37 (3/4): 257-261, Jul./Dec. 1984.

\section{REFERENCIAS BIBLIOGRÅFICAS}

CONSELHO TEDERAL DE ENFERMAGEM. Enfermagem brasileira em defesa dos seus direitos. Rio de Janciro, 1980.

FRIEDL.ANDER, M.R. Prescrição diária da enfermagem: condiçōes para sua implantaçĩo como atividade de rotina da cnfermcira. Rev. Esc. Enf. USP, São Paulo, $7(2): 177-85,1973$.

GOMLS, A.M. Enfermagem na unidade de terapia intensiva. Sĩo linulo, ElPU, 1978. 149 p.

KOCH, R.M. \& OKA, L.N. Processo de cnfermagem: aviliação fcita pelos alunos do Departamento de Enfermagem da UCP. Rev. Bras. Enf., Brasília, 30 (3): 274-285, jul./out. 1977.

MIZUTANI, L.K. Plano de cuidados: elaboração e utilização de um impresso cm uma clínica de dermatologia. Enf. Novas Dimens., Sĩo Puulo, 4 (4): 203-11, jul./ago. 1978.

WHIPPLE, G.H. ct alii. Ó processo de cnfermagem. In: . Insuficiência coronária: assistência e trata-

mento. São Paulo, El'U, 1980. cap. 9, p. 119-124. 